\title{
Interannual and decadal covariabilities in East Asian and Western North Pacific summer rainfall for 1979-2016
}

\author{
Seogyeong Kim ${ }^{1,2} \cdot$ Kyung-Ja Ha ${ }^{1,2}$ (])
}

Received: 30 December 2019 / Accepted: 26 October 2020 / Published online: 8 November 2020

(c) The Author(s) 2020, corrected publication 2020

\begin{abstract}
Understanding the variabilities of East Asian summer rainfall (EASR) and Western North Pacific summer rainfall (WNPSR) is essential because they play a key role to control the energy and water supply. Monsoon index is generally defined by seasonal mean, but it is not appropriate for considering various timescale characteristics. Because it includes the influence of not only the interannual but also longer timescales. Thus, the several timescale variances in the indices and background fields should be isolated as each variability to focus on their own features. Here, the present study defines the EASR and WNPSR indices to explore potential factors that may trigger the enhanced rainfall for the period 1979-2016. Interannual variation is shown to be dominant in both indices, while decadal variation is more significant in WNPSR than EASR. Each index is decomposed to obtain a signal on interannual and decadal timescales with 1-7 and 8-15 years. The interannual components in both indices perform opposite each other in atmospheric and oceanic fields and have a negative relationship with high covariance. Both location of subtropical jet and thermal condition over the Indian Ocean contribute to interannual EASR and WNPSR as factors. In contrast, related fields upon both decadal indices represent distinguished patterns. The EASR is modulated by Pacific sea surface temperature anomalies (SSTA) and interdecadal oscillation patterns in the decadal timescale. However, the WNPSR is controlled by the tri-polar SSTA over the North Atlantic. Consequently, the decadal and interannual variabilities show differing mechanisms to adjust rainfall during monsoon events.
\end{abstract}

Keywords East Asian summer monsoon · Western North Pacific summer monsoon · Interannual variability · Decadal variability

\section{Introduction}

The monsoon features a remarkable seasonal wind reversal in the large-scale circulation system, driven by differential heating on a continent and ocean. Additionally, moisture transport could have an impact on monsoon onset and intensity. Many studies conventionally have defined monsoon indices using precipitation and dynamic components that explain the horizontal and vertical wind shear (Shukla and Mooley 1987; Wang and Fan 1999; Li and Zeng 2002).

The Asian summer monsoon contains three subsystems, namely the East Asian summer monsoon (EASM),

Kyung-Ja Ha

kjha@pusan.ac.kr

1 Center for Climate Physics, Institute for Basic Science (IBS), Busan 46241, South Korea

2 BK21 School of Earth and Environmental Systems, Pusan National University, Busan 46241, South Korea
Western North Pacific summer monsoon (WNPSM), and South Asian summer monsoon (SASM). The unique topography and location of monsoon produce distinctive features. Especially, the positions of EASM and WNPSM area are adjacent, but they show different features such as their variabilities and governing factors. In the EASM, the northwestward extended rainband is designated as Meiyu, Baiu, and Changma that locates in East Asia encompassing China, Japan and, Korea (Lau et al. 1988; Ninomiya and Akiyama 1992). The EASM accompanies the Western North Pacific subtropical high (WNPSH) and it performs a role to transport moisture through the southwesterly flow over East Asia (Ding and Chan 2005; Ha et al. 2012). The WNPSM dominates over the Philippine Sea and is affected by the inter-tropical convergence zone (ITCZ) on the WNP weather system, such as the birth of typhoons and tropical convective systems (Murakami and Matsumoto 1994; Ding 2007). According to Wang and Ho (2002), the EASM is categorized 
as a continental and subtropical monsoon and the WNPSM is classified as an oceanic and tropical monsoon.

The EASM and WNPSM include variabilities over a variety of timescales, such as intraseasonal, interannual, decadal, and interdecadal timescale (Lau 1992; Ding and Chan 2005; Ha et al. 2012; Huang et al. 2013). More than half of the world's population lives in the Asian monsoon region. The diverse variabilities of these monsoons give rise to severe flooding, drought, and other disasters, and their lives are dependent on the monsoon variability. In particular, the interannual variability of monsoons gets directly connected to serious economic and social problems from disasters. Thus, understanding the interannual variability of EASM and WNPSM will be beneficial for water management plans of damaged countries. Their interannual variabilities are considerably tied to some climate systems and interannual relationship with El Niño-Southern Oscillation (ENSO) has been widely accepted. A strong EASM may occur after the mature phase of a warm ENSO with a positive relationship and a cold state in the equatorial central-eastern Pacific is following in next winter. Because the Meiyu/Baiu rainfall distribution tends to be contemporaneously an anti-phase to WNPSM rainfall distribution, a weak WNPSM develops concurrently with strong EASM (Zhang et al. 1996; Wu and Wang 2000; Wang et al. 2001; Lee et al. 2010). Several sea surface temperature anomalies (SSTA) patterns over the Indian Ocean, Indian Ocean dipole (IOD), and Indian Ocean basin (IOB) modes have also influenced monsoon circulations by producing Rossby wave patterns (Guan and Yamagata 2003; Kripalani et al. 2010). Besides, the teleconnection from the Atlantic and Arctic via the upper-level flow, Rossby wave, and transient eddies can be a key role in the interannual variability of EASM and WNPSM (Gong and Ho 2003; Zhang et al. 2006; Gong et al. 2011; Park et al. 2015; Chen and Bordoni 2016).

There is an increasing demand for the decadal prediction in the monsoon system because forecasting monsoon changes in the coming decade is critical to set the infrastructure planning, energy policy, and sustainable development. Furthermore, interannual variability can be modulated by decadal variability. Especially, the investigation of climate shift and evolution of the monsoon climate state in longer timescale are generally included in the prediction for seasonal and interannual variability as background conditions. Progress has been made in documenting and understanding decadal variations in monsoon precipitation in individual monsoon region (Goswami et al. 2006; $\mathrm{Lu}$ et al. 2006; Kwon et al. 2007; Gu et al. 2009; Ding et al. 2010; Wu et al. 2012; Wang et al. 2013, 2018; Yim et al. 2014; Yun et al. 2018; Kim et al. 2018). The contribution of decadal variation to the total variation is generally smaller than that observed in the interannual variation. However, the high frequency of intensive rainfall on the total variability is potentially linked to the positive decadal phase. The intensity of year-to-year time-series can be reinforced (offset) when the decadal phase is identical (opposite) to the interannual phase, respectively. Therefore, it is necessary to improve the understanding of the decadal timescale in EASM and WNPSM.

Numerous studies have confirmed the longer period variation in Asian monsoon by examining the notable phase transition in the interannual relationship between monsoon and some climate phenomena. (Kwon et al. 2007; Ding et al. 2010; Wu et al. 2012; Kim et al. 2018; Yun et al. 2018). However, the approaches used frequently in previous studies to identify the variability of monsoon are not prone to not explore their variabilities in each monsoon. Few studies have highlighted monsoon's robust variabilities by period filtering and suggested to examine which factor fluctuates with the same variance and controls each variability in monsoon events (Gu et al. 2009; Wang et al. 2013, 2018). It is difficult to examine the factor modulating specific timescale variance by using raw data. It is because the raw data is combined with multiple timescales. This study involves a decomposition analysis of variabilities to isolate the dominant periods. It also explores and compares the spatial rainfall distribution for each monsoon on each timescale to connect with the phenomenon having the same periodicity. We suggest the factors regulating the rainfall intensity with possible mechanisms. The paper is organized as follows: Sect. 2 covers methods, and the data obtained. Section 3 highlights atmospheric and oceanic anomalies associated with EASM and WNPSM on each timescale and infers their causes and mechanisms. Section 4 covers a summary and the discussion.

\section{Data and method}

\subsection{Data}

The monthly datasets analyzed in the present study are the atmospheric circulation data obtained from the ERAINTERIM for the European Centre for Medium-Range Weather Forests (ECMWF; Dee et al. 2011) and the National Centers for Environmental Prediction-National Center for Atmospheric Research (NCEP-NCAR; Kalnay et al. 1996). Further, monthly precipitation data are derived by the Global Precipitation Climatology Project (GPCP; Adler et al. 2003) and sea surface temperature (SST) data are provided by the Extended Reconstructed SST, version 5 (ERSST.v5; Huang et al. 2017) from the National Oceanic and Atmospheric Administration (NOAA). Dataset details are described in Table 1. This study focuses on the boreal summer (June-July-August, JJA) from 1979-2016. 
Table 1 Datasets used in this study

\begin{tabular}{llll}
\hline Dataset & Variable & \multicolumn{2}{l}{ Analysis output grid } \\
\cline { 3 - 4 } & & Horizontal & Pressure \\
\hline NCEP & $\begin{array}{c}\text { Geopotential height, U } \\
\text { wind, V wind }\end{array}$ & $144 \times 73$ & 17 Levels \\
ERA-Interim & 2 m air temperature & $240 \times 121$ & 1 Level \\
ERSST.v5 & Sea surface temperature & $180 \times 89$ & 1 Level \\
GPCP & Precipitation & $144 \times 72$ & 1 Level \\
APHRODITE & Precipitation & $360 \times 280$ (Asia) & 1 Level \\
\hline
\end{tabular}

\subsection{Definition of East Asian and Western North Pacific summer rainfall index}

The major variability in the precipitation and circulation over East Asia and the WNP has been addressed in previous studies (Ding 2007; Ha et al. 2009, 2012; Lee et al. 2014; Oh and $\mathrm{Ha} 2015,2016)$. Following Li and Zeng (2002), the JJA averaged dynamical index for EASM has been conducted by using the area-averaged horizontal wind at $850 \mathrm{hPa}$ over the regions encompassing East Asia and the WNP $\left(10^{\circ} \mathrm{N}-40^{\circ} \mathrm{N}\right.$, $\left.110^{\circ} \mathrm{E}-140^{\circ} \mathrm{E}\right)$. This EASM dynamical index represents anomalous anticyclonic circulation over East Asia and cyclonic circulation over the WNP as a meridional dipole pattern. This pattern has shifted on the interannual, decadal, and interdecadal timescale (Ding et al. 2010; Kim et al. 2018). Figure 1a shows the regressed precipitation distribution during boreal summer against the JJA averaged dynamical EASM index for 1979-2016. The spatial precipitation pattern significantly delineates a remarkable meridionally dipole-like pattern over East Asia and the WNP. The distinguished wetness and dryness patterns are zonally elongated and these regions are separated into East Asia and the WNP marked with red and blue boxes in Fig. 1a, respectively. Thus, we formulate the JJA averaged East Asian summer rainfall index (EASRI) and Western North Pacific summer rainfall index (WNPSRI) by area-averaging precipitation amount over East Asia $\left(30^{\circ} \mathrm{N}-40^{\circ} \mathrm{N}, 100^{\circ} \mathrm{E}-150^{\circ} \mathrm{E}\right)$ and the WNP $\left(10^{\circ} \mathrm{N}-25^{\circ} \mathrm{N}, 115^{\circ} \mathrm{E}-150^{\circ} \mathrm{E}\right)$ regions to represent rainfall distribution across each monsoon. The rainfall indices explain the regressed precipitation patterns in each region in itself (Fig. 1b and 1c).

\subsection{Wavelet analysis and bandpass filtering}

To identify the dominant periodicity and factors which contribute to EASRI and WNPSRI in each timescale, this study applies the Morlet mother wavelet analysis (Torrence and Compo 1998) and the Lanczos bandpass filter. In Fig. 2a and b, the shading and line denote the wavelet power in each timescale. The EASRI has a manifested power spectrum in the 1-7 year period and a lesser power (a) Dynamical EASM index (PRCP)

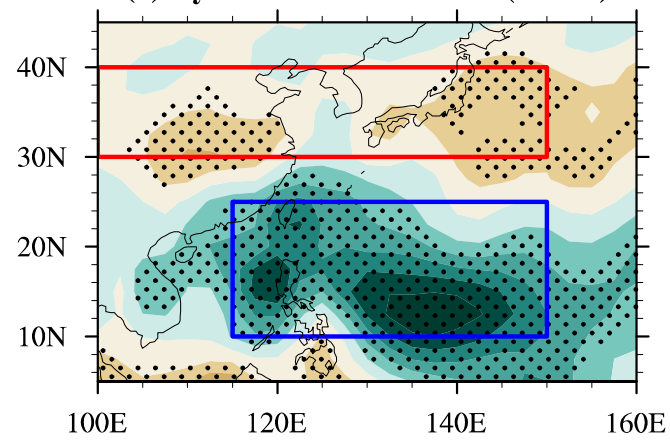

(b) EASRI (PRCP)

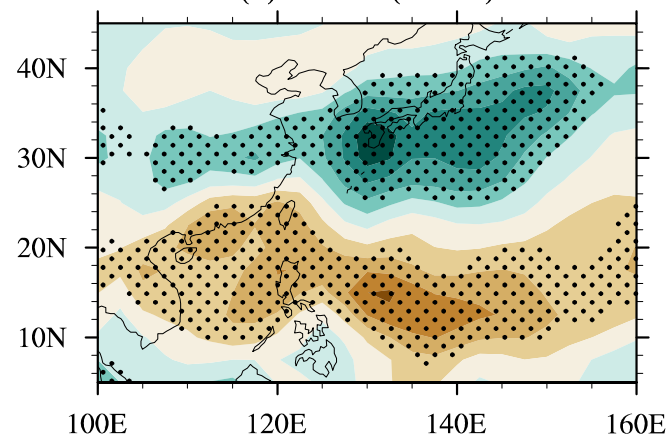

(c) WNPSRI (PRCP)
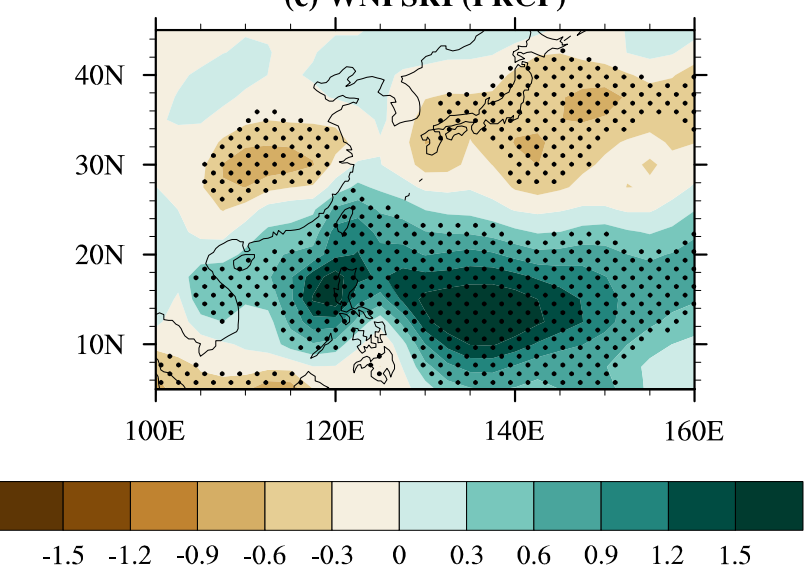

Fig. 1 a Spatial distribution of regressed precipitation with respect to the dynamical EASM index defined by Li and Zeng (2002). The red and blue boxes are the regions used to formulate the EASRI and WNPSRI by area-averaged precipitation in each region for JJA. The regressed rainfall patterns against (b) EASRI and (c) WNPSRI are represented. The shading denotes the value of precipitation (shading, unit: mmday $^{-1}$ ) and the stippling represents the statistical significance above the $90 \%$ confidence level based on the Student's t-test

spectrum in periods longer than 7 years. In contrast, the WNPSRI has a clear power spectrum in periods of both $1-7$ and $8-15$ years. Thus, we decompose EASRI and WNPSRI to achieve a strong signal at interannual and decadal timescales for the periods of years 1-7 and 8-15 (Fig. 2c and d). All indices used in this study are 
(a) Wavelet of EASRI

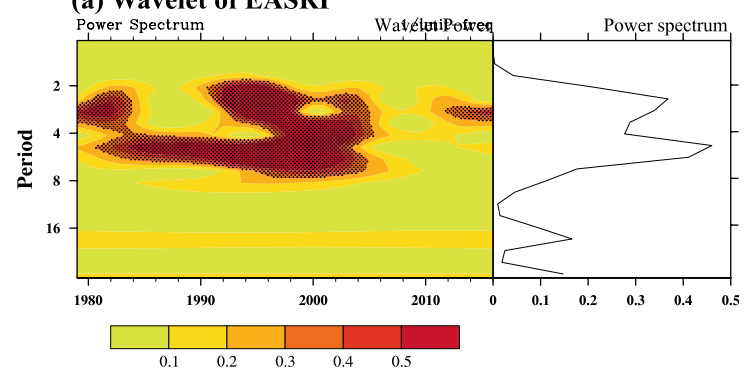

(c) Time series of EASRI in IAV and DV scale

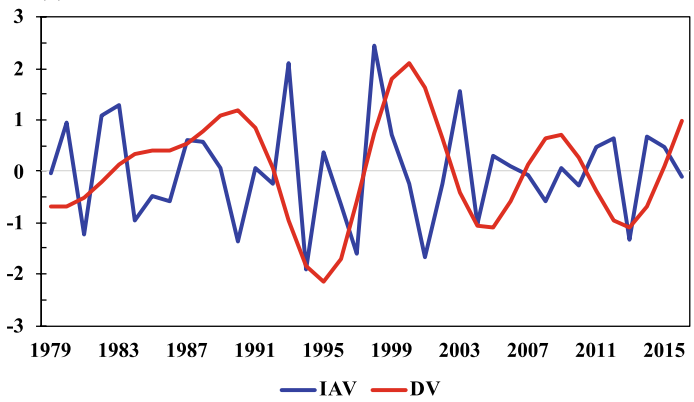

Fig. 2 Results of wavelet analysis in EASRI and WNPSRI for 19792016. a, b The wavelet power of EASRI and WNPSRI are described by shading and the power spectrums in each time peridoicity are

averaged for JJA season and then are applied to the Lanczos bandpass filter with both period bands. In all fields, we eliminate the annual cycle by subtracting the monthly climatology from the monthly field. After that, fields are filtered by the Lanczos bandpass filter to contemplate the climate phenomenon for the continuous season and then the JJA averaging is performed. We compare distinct features in circulation distributions against EASRI and WNPSRI on each timescale and determine the linkages with other climate systems. To obtain the relationship of EASRI (WNPSRI) with anomalous seasonal patterns, the JJA averaged climate indices are produced and filtered by corresponding timescales; then, all indices have been linearly detrended and standardized by population standard deviations. In this study, the statistical analysis such as linear regression and correlation coefficient are operated. We mark the significance of the correlation coefficient at 90,95 , and $99 \%(0.9,0.95$, and 0.99) confidence level with the number of asterisk such as $*, * *$, and $* * *$, respectively. The evaluation of the significance level is assessed by Student's t-test with an effective number of degrees of freedom based on the lag 1 autocorrelation (Bretherton et al. 1999). Especially, in the decadal timescale, the corresponding effective number of degrees of freedom is greatly reduced in all indices and all fields due to the bandpass filtering and the equivalent sample sizes of decadal fields do not coincide in each grid (not shown).

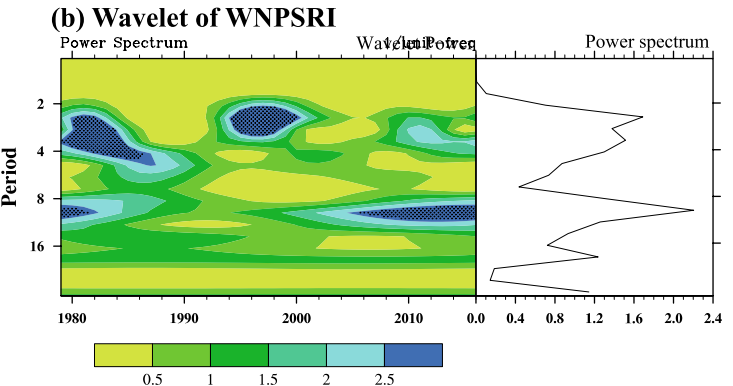

(d) Time series of WNPSRI in IAV and DV scale

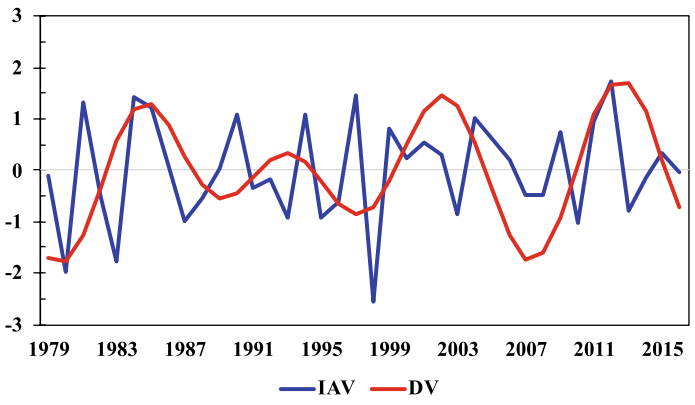

shown as the line. c, d The normalized time-series of EASRI and WNPSRI on the interannual (blue line) and decadal (red line) timescales

\section{Results}

\subsection{Impact of East Asian and Western North Pacific summer rainfall}

The boreal summer rainfall over East Asia and WNP has active interaction with the various climate systems in multitimescale. Because variabilities in EASM and WNPSM are controlled by combined influences from several factors in different timescales, it is necessary to examine the factor in the extracted periods. To investigate the influence of EASRI and WNPSRI on surface temperature and atmospheric circulation anomalies during boreal summer, we describe the linear regressed distributions against these monsoon indices. The filtered and JJA averaged SST, surface air temperature (SAT), and atmospheric circulation anomalies related to filtered EASRI and WNPSRI have been assessed on the interannual and decadal timescales in Figs. 3 and 4 , respectively. The regressed spatial distributions against the interannual EASRI (WNPSRI) bear resemblance to those against the unfiltered EASRI (WNPSRI) because the interannual variability contributes considerably to total variability (not shown). The interannual EASRI is significantly associated with a warm signal over the WNP expanding into India encompassing the northern Indian Ocean (NIO), and eastern Pacific. We attribute the warming over WNP and NIO to subsidence from surface anticyclonic wind anomalies and increased insolation from the reduced clouds. In 
(a) IAV EASRI (SST, SAT)

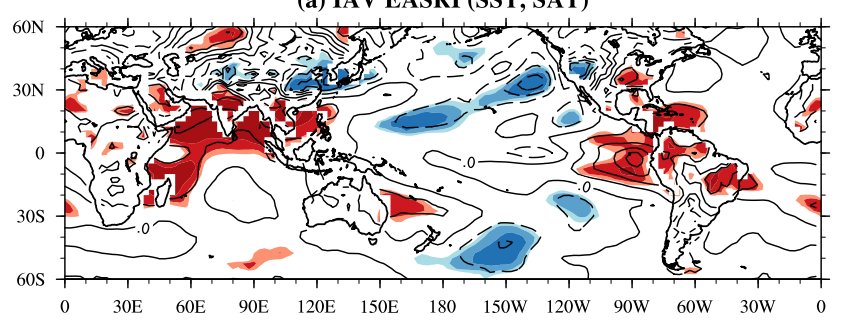

(b) IAV WNPSRI (SST, SAT)

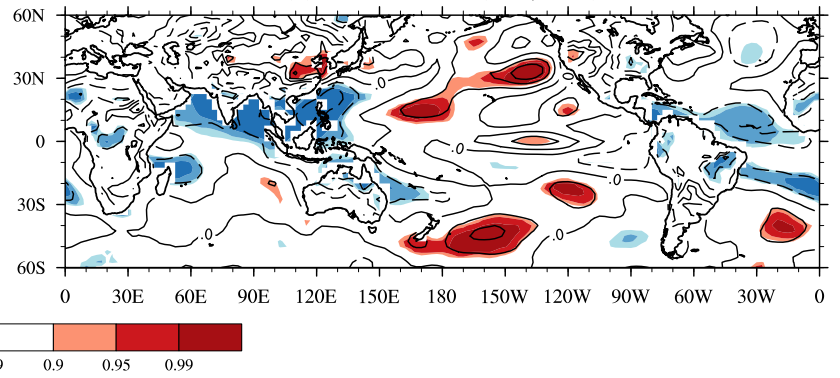

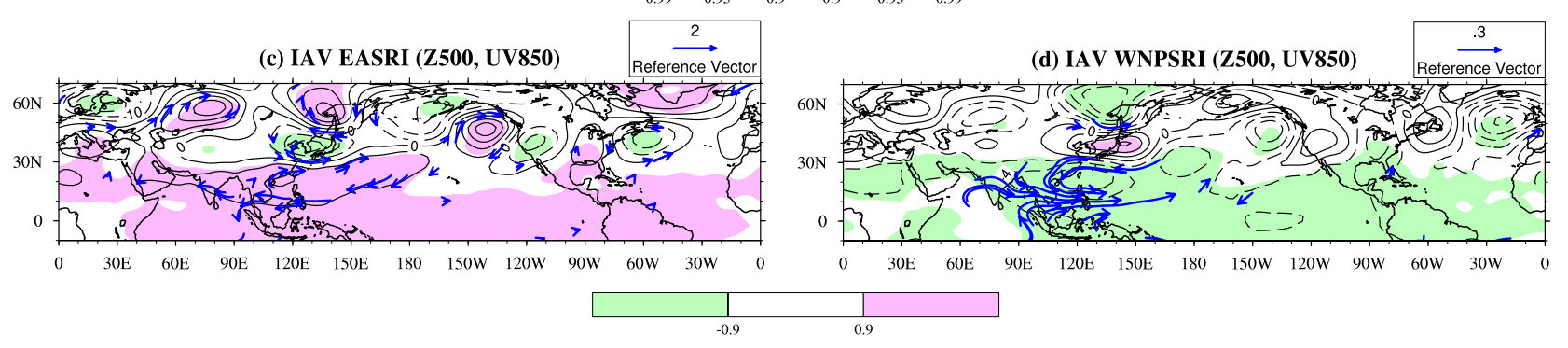

Fig. 3 The regressed sea surface temperature and surface air temperature (contour, unit: $\mathrm{K}$ ), geopotential height at $500 \mathrm{hPa}$ (contour, unit: $\mathrm{gpm}$ ), and horizontal wind at $850 \mathrm{hPa}$ (vector, unit: $\mathrm{ms}^{-1}$ ) distribution against EASRI $(\mathbf{a}, \mathbf{c})$ and WNPSRI $(\mathbf{b}, \mathbf{d})$ on the interannual timescale. The shading from light to dark color in the surface tempera- ture distribution indicates the statistical significance at the 90,95 , and $99 \%(0.9,0.95$, and 0.99$)$ confidence level and that in the geopotential height distribution show the significance at $90 \%$ (0.9) confidence level evaluated by the Student's t-test based on the effective number of degrees of freedom (a) DV EASRI (SST, SAT)

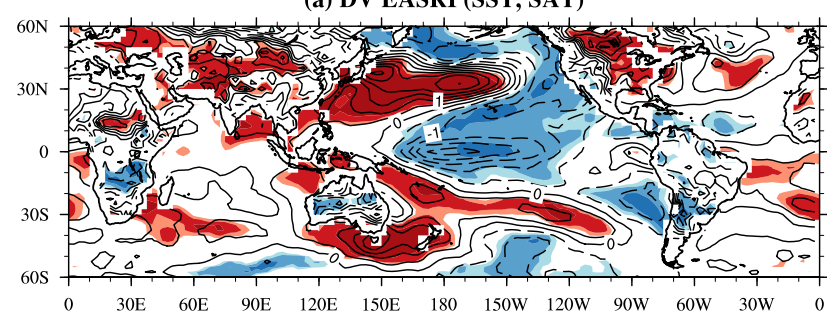

(b) DV WNPSRI (SST, SAT)

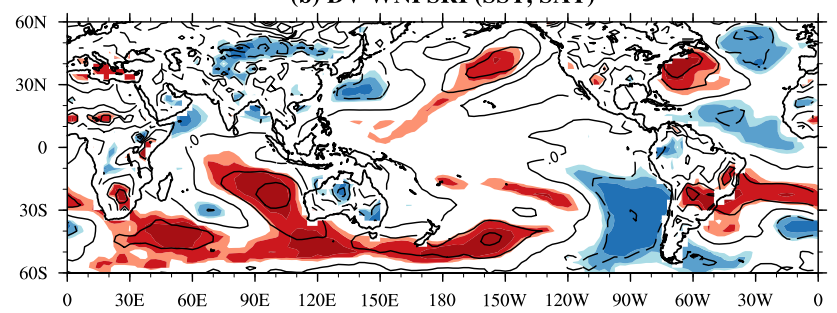

\begin{tabular}{l|l|l|l|l|l|l}
\hline & & & & & & \\
\hline
\end{tabular}

(c) DV EASRI (Z500, UV850)

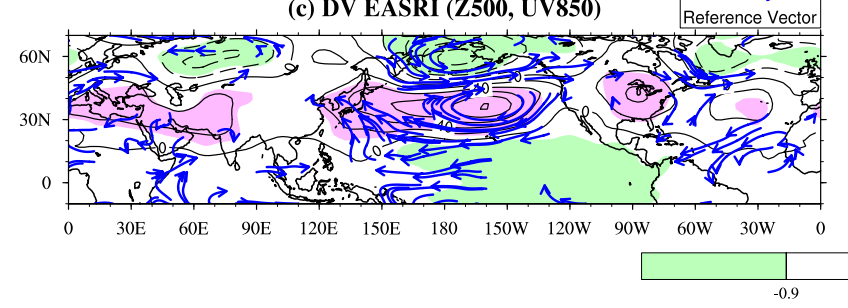

(d) DV WNPSRI (Z500, UV850)

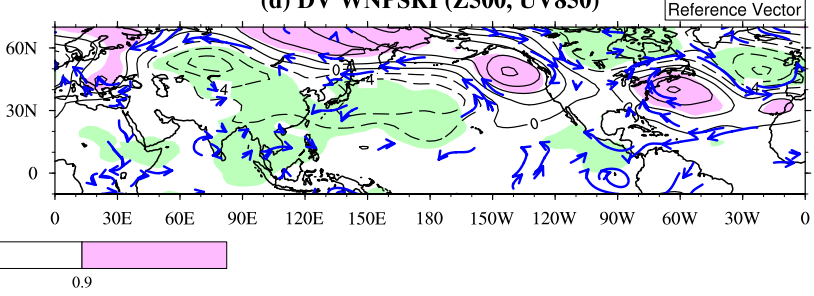

Fig. 4 Same as Fig. 3 except for decadal timescale

the eastern Pacific, the warming SST has been associated with the preceding boreal winter warm ENSO. The cooling over East Asia may be affected by its rainfall (Fig. 3a). The geopotential height anomalies are organized into a meridional dipole with anticyclone in the tropical WNP expanding into the NIO area, and cyclone in East Asia, like dominant
Pacific-Japan (PJ) pattern (Nitta 1987) (Fig. 3c). The PJ pattern features the circulation dipole centers over the Philippine Sea and Japan and this teleconnection is a crucial signal for both interannual monsoon events. Additionally, the wave train-like pattern in the mid-latitude that supports wave propagation via teleconnection is shown. 
The spatial patterns against interannual WNPSRI are nearly reversed to those against interannual EASRI. They are represented by a cooling signal over the NIO and WNP, a warming signal over East Asia, and a meridional dipole geopotential height pattern (Fig. $3 b$ and d). This meridional circulation dipole pattern seems to be more definite than shown in Fig. 3c, especially the circulation center over WNP. The relationship between interannual EASRI and WNPSRI is significantly negative, as shown by a correlation coefficient of $-0.61 * * *$ which is significantly above the $99 \%$ confidence level. To surmise the covariation between interannual EASR and WNPSR, we apply to the first empirical orthogonal function (EOF) mode of precipitation over East Asia and the WNP $\left(10^{\circ} \mathrm{N}-40^{\circ} \mathrm{N}, 100^{\circ} \mathrm{E}-150^{\circ} \mathrm{E}\right)$ (not shown). A prominent precipitation dipole pattern exhibit meridionally and it explains approximately $28.6 \%$ of the total variation. Therefore, the wet East Asia and dry WNP in rainfall distribution (or vice versa) covariate on the interannual timescale. However, inconsistency also exists in spatial regressed distributions. Significant warming over the eastern Pacific is shown in the regressed distribution upon EASRI but not in that upon WNPSRI. In contrast, a cooling signal over the tropical Atlantic displays in the regression against WNPSRI which does not exist in that against EASRI. Additionally, tri-pole geopotential height at $500 \mathrm{hPa}$ distribution and wave train pattern in the mid-latitude are represented in both regressed circulation distributions with different significances. In particular, the signals against EASRI (WNPSRI) are more prominent in the mid-latitude (tropics), respectively.

Surprisingly, the regressed spatial distributions against decadal EASRI are distinguished from those against decadal WNPSRI (Fig. 4), unlike interannual monsoon indices. The La Niña-like SSTA pattern and anomalously enhanced subtropical high over North Pacific at $500 \mathrm{hPa}$ are associated with decadal EASRI (Fig. 4a and c). The oceanic signal appears over both Pacific and Atlantic and most dominant is over the Pacific. In contrast, the regressed surface temperature distribution upon the decadal WNPSRI exhibits a significant tri-pole signal over the North Atlantic (Fig. 4b). Notably, the surface temperature pattern against the decadal WNPSRI appears less significant over the Pacific, unlike in the decadal EASRI. The huge cyclonic circulation anomalies cover the Eurasian continent, including the North Pacific region (Fig. 4d). Finally, the decadal variances in the EASRI and WNPSRI do not share a significant relationship with the correlation coefficient of 0.02 and do not covariate, unlike interannual monsoon indices. This is the reason why we decompose both monsoon indices on each interannual and decadal timescale to show the matched phenomenon. The specific regressed patterns are produced on the interannual and decadal timescales, and different factors are expected to control each rainfall patterns in itself; this is true for both indices. Therefore, the present study proposes to consider periodicity as interannual and decadal timescales separately.

\subsection{Sources for EASRI and WNPSRI on the interannual timescale}

\subsubsection{EASRI}

Which climate system has closely linked to EASRI on the interannual timescale? As mentioned above, the regressed thermal signals and large circulation against interannual EASRI (WNPSRI) are more notable in the mid-latitudes (tropics). We focus on the mid-latitude (tropical) climate systems to find factor adjusting the East Asia (WNP) region rainfall distributions, respectively. Under the regressed atmospheric circulation distribution against interannual EASRI, the positive phase of EASRI is significantly associated with the zonally elongated wave train in the midlatitudes. In the boreal summer, the teleconnection wave train-like pattern emanates along the subtropical westerly jet stream, and the jet stream plays a role of the waveguide by trapping the wave (Enomoto et al. 2003; Ding and Wang 2005). Figure 5a illustrates a boreal summer climatology and the first mode of EOF in the zonal wind at $200 \mathrm{hPa}$ from $1979-2016$ over the area $\left(25^{\circ} \mathrm{N}-55^{\circ} \mathrm{N}, 40^{\circ} \mathrm{E}-150^{\circ}\right.$ E). The notable westerlies are manifested over the Tibetan Plateau in the climatological distribution. We identify the variance of the movement and intensity of the subtropical jet stream in the major spatiotemporal mode comparing to the climatology. The first EOF mode accounts for $26.19 \%$ of the total variance and the positive and negative signals denote meridionally movement of the jet stream near East Asia. The positive phase of the principal component (PC) for the first EOF mode infers the poleward shift in the subtropical jet stream. To quantify the meridional shift of it, we formulated the jet stream meridional displacement index (JMDI) by subtracting the JJA averaged and area-averaged zonal wind at $200 \mathrm{hPa}$ from the north area $\left(40^{\circ} \mathrm{N}-55^{\circ} \mathrm{N}, 40^{\circ} \mathrm{E}-150^{\circ} \mathrm{E}\right)$ to the south area $\left(25^{\circ} \mathrm{N}-40^{\circ} \mathrm{N}, 40^{\circ} \mathrm{E}-150^{\circ} \mathrm{E}\right)$. A positive JMDI suggests the northward jet stream shift relative to the climatological position, and vice versa. The JMDI represents well the PC of the first EOF mode with a correlation coefficient of $0.94 * * *$ that is significant at the $99 \%$ confidence levels based on Student's t-test. And then, we filter it on the interannual timescale to match with interannual EASRI.

The atmospheric circulation pattern against the negative phase of JMDI is closely resembling that against EASRI and shows the tri-polar geopotential height distribution including PJ pattern and wave train-like pattern in the mid-latitudes (Fig. 5b). The mid-latitudinal signals stand out more clearly than in tropics. We propose a possible mechanism for the control of rainfall patterns over East Asia via the meridional shift of subtropical jet stream. When the subtropical 
Fig. 5 a Climatological mean distribution (shading, unit: $\mathrm{ms}^{-1}$ ) and the first EOF mode (contour, unit: $\mathrm{ms}^{-1}$ ) of zonal wind at $200 \mathrm{hPa}$ from 1979-2016. b The regressed geopotential height at $500 \mathrm{hPa}$ (contour, unit: gpm) and horizontal wind at $850 \mathrm{hPa}$ (vector, unit: $\mathrm{ms}^{-1}$ ) distribution against the negative phase of JMDI. c The scatter plot between interannual EASRI and JMDI and their correlation coefficient (CC). The shading in the regressed geopotential height indicates the statistical significance at the $90 \%$ (0.9) confidence level evaluated by the Student's t-test based on the effective number of degrees of freedom (a) Climatology of U200, EOF mode1 of U200 (26.19\%)
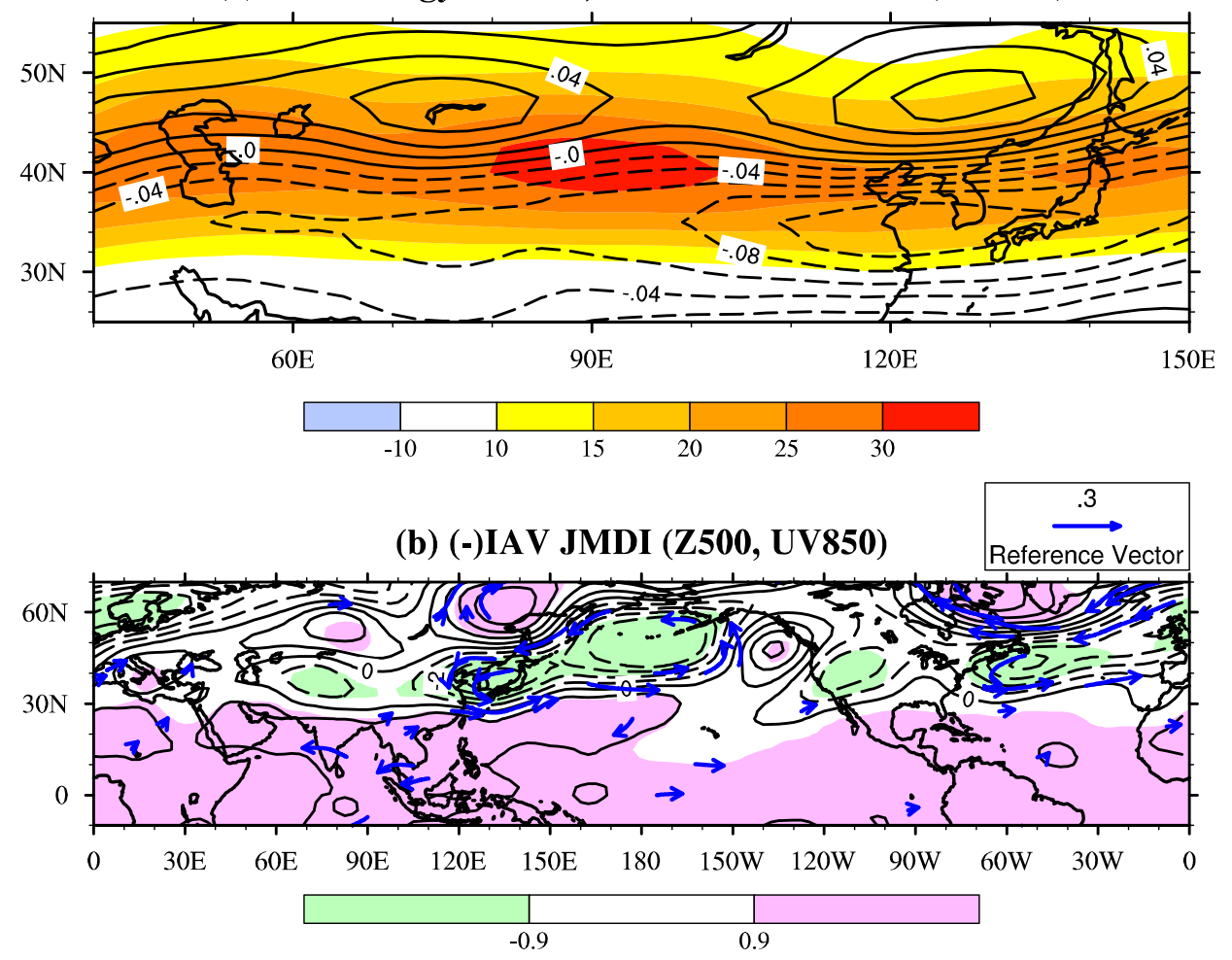

(c) Scatter Plot

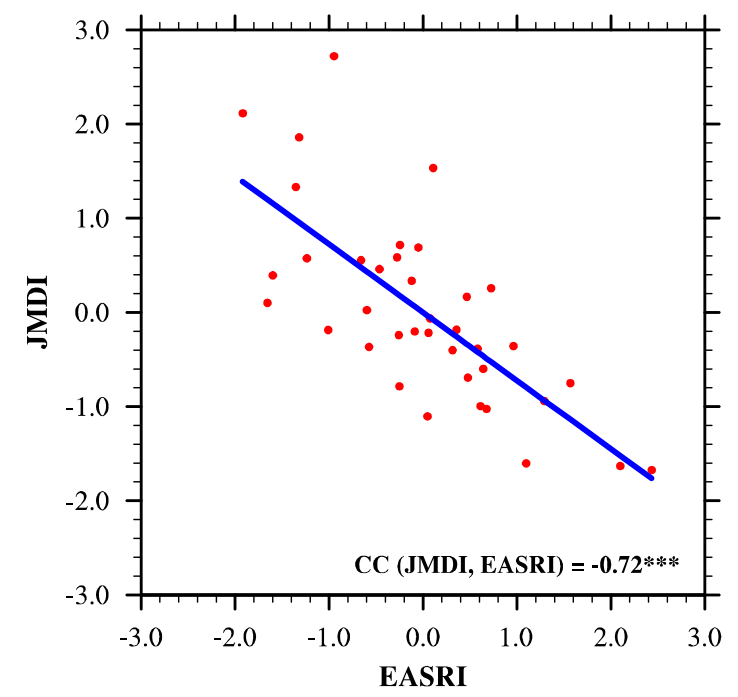

jet stream is located in the south part of the climatological jet stream, the anomalous westerlies at $200 \mathrm{hPa}$ overlap the south of Korea and Japan. Because the mid-latitudes exhibit a quasi-barotropic structure, the anomalous westerly wind is also observed at a low level. Subsequently, the anomalous cyclonic circulation is performed and it may be related to increased rainfall over East Asia. The scatter plot depicts the negative relationship between interannual EASRI and JMDI with a linearly regressed blue line and their correlation coefficient between two indices is $-0.72 * * *$ (Fig. 5c). Therefore, the displacement of upper-level zonal wind and East Asian precipitation distribution are statistically related. To confirm the impact of the preceding meridional location of the subtropical jet stream for the preceding seasons, we describe the lead-lag relationships between JJA( $(0)$ averaged EASRI and 3-month averaged JMDI, which is preceding and following the EASRI in Fig. 7a. Because their relationship is significantly negative only for the boreal summer, the only 
contemporary subtropical jet stream location may modify the rainfall distribution over East Asia.

Then, what does modulate the subtropical jet stream displacement? The meridional shift of upper-level zonal wind is tied to the local meridional temperature gradient, heating over the Tibetan Plateau, and the interaction between the mean flow and transient eddies (Park et al. 2015; Chen and Bordoni 2016). According to Oh and Ha (2020), they suggest the impact of two boundary conditions for East Asia rainfall that is associated with upper-level zonal wind. That is snow cover over eastern Eurasia during preceding boreal spring and SST tendency over WNP can induce the re-displacement of the thermal condition and the subtropical jet stream. Additionally, the phase of preceding Arctic oscillation (AO) also can be a potential contributor to change the subtropical jet stream placement and intensity of East Asia rainfall (Gong and Ho 2003; Gong et al. 2011).

\subsubsection{WNPSRI}

We explore the surface temperature and atmospheric circulation patterns associated with interannual WNPSRI to find factors that modify rainfall distribution over the WNP. Figure $3 b$ shows significant cooling signals over both the South China Sea and the NIO. Although significant signals are illustrated in both locations, we focus on the only cooling signal over NIO because a part of the South China Sea cooling may result from rainfall over the WNP. We formulate the North Indian Ocean index (NIOI) by area-averaged SSTA over the NIO region $\left(0^{\circ}-25^{\circ} \mathrm{N}, 50^{\circ} \mathrm{E}-100^{\circ} \mathrm{E}\right)$ during the boreal summer. And then, the NIOI is filtered by a 1-7 year band. Figures $6 a$ and $6 b$ show anomalous surface temperature and atmospheric circulation distribution against the negative phase of NIOI on the interannual timescale. A cooling signal over NIO and the South China Sea, as well as the meridional dipole structure in the geopotential height, are similar to Fig. $3 b$ and d, respectively. Figure $6 a$ and $b$ display the significant La Niña-like pattern in surface temperature and shows a more clear PJ pattern than Fig. 5b. The scatter plot certifies the negative relationship between interannual WNPSRI and NIOI with a linearly regressed blue line and the correlation coefficient between them is $-0.51^{* * *}$ (Fig. 6c). The intensity of WNP rainfall during boreal summer is affected by not only contemporary but also preceding cooling NIO. The relationship between JJA averaged WNPSRI and 3-month averaged NIOI from the preceding boreal winter to concurrent boreal summer is persisted and considerably significant above the $99 \%$ confidence level (Fig. 7b). The cooling NIO may persist for several seasons because the cooling NIO is based on SST and has the characteristic of being maintained, unlike the jet stream. When the anomalous cold condition sustains until boreal summer, it excites a tropospheric cold Kevin wave penetrating the western Pacific. Finally, this Kelvin wave induces the surface Ekman convergence over the Philippine Sea and supports the enhanced rainfall anomalies over WNP (Yang et al. 2007).

The thermal pattern over IO is essential for summer climate variability in the Indo-western Pacific region and it is associated with boreal winter ENSO, but no just passive response to ENSO. Most of the cooling (warming) pattern over IO follows La Niña (El Niño) events via anomalous Walker circulation. When the eastern Pacific SST anomalies are dissipated in the following boreal summer, the thermal condition over IO is sustaining as a capacitor and the generated wave causes the change in rainfall distribution over WNP (Xie et al. 2009). The lead-lag relationships between boreal summer WNPSRI and 3-month averaged NIOI and Niño 3.4 index which are preceding and following the WNPSRI are described in Fig. 7 and it is consistent with Yang et al. (2007). The Niño 3.4 index is operated and derived by NOAA's Climate Prediction Center (CPC).

Furthermore, we suggest factors for enhancing rainfall over East Asia (WNP) in the mid-latitude (tropical) climate systems, respectively. However, the southward shift of the subtropical jet stream (cooling signal over the NIO) is not independent factors and can influence anomalous decreasing rainfall over the WNP (East Asia), respectively. Figure 8 shows the spatial regressed precipitation against the negative phase of JMDI and NIOI, and the meridional dipole patterns appear in both rainfall distribution. In the negative phase of the JMDI, the dry signal over the WNP in dipole pattern is significant, but it is less zonally elongated than that against EASRI. On the other hand, against the negative phase of NIOI, the significant dryness over East Asia is zonally stretched, similar to WNPSRI. We examine the co-variability of rainfall dipole patterns and zonal wind at $200 \mathrm{hPa}$ (surface temperature over the NIO) by using a singular value decomposition (SVD) analysis for 1979-2016. The first SVD mode represents the meridional shift of jet stream (cooling signal over NIO) and meridional dipole rainfall patterns over East Asia and the WNP. It explains approximately $58.11 \%(77.73 \%)$ of the total squared covariance (not shown). Consequently, JMDI and NIOI may also influence the rainfall distribution and large anomalous circulation over both regions.

\subsection{Sources for EASRI and WNPSRI on the decadal timescale}

\subsubsection{EASRI}

In the decadal timescale, the variances and the response to external forcing often occur beyond regional scales, and a regional approach is not appropriate to identify overriding and planetary-scale controls (Wang et al. 2013; Yim et al. 2014). Besides, to act as a cause on the decadal timescale, 
Fig. 6 a Surface temperature (contour, unit: K) and (b) geopotential height at $500 \mathrm{hPa}$ (contour, unit: gpm) and horizontal wind at $850 \mathrm{hPa}$ (vector, unit: $\mathrm{ms}^{-1}$ ) distribution against the negative phase of NIOI. c The scatter plot between interannual WNPSRI and NIOI and their correlation coefficient. The shading from light to dark color in the surface temperature distribution indicates the statistical significance at the 90, 95, and $99 \%(0.9,0.95$, and 0.99$)$ confidence level and that in the geopotential height distribution show the significance at $90 \%$ (0.9) confidence level evaluated by the Student's t-test based on the effective number of degrees of freedom

(a) (-)IAV NIOI (SST, SAT)

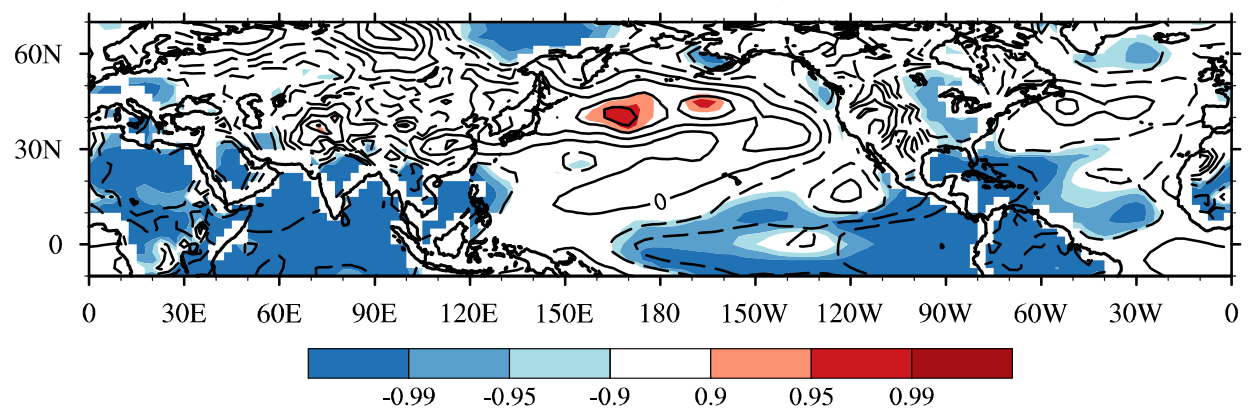

(b) (-)IAV NIOI (Z500, UV850)

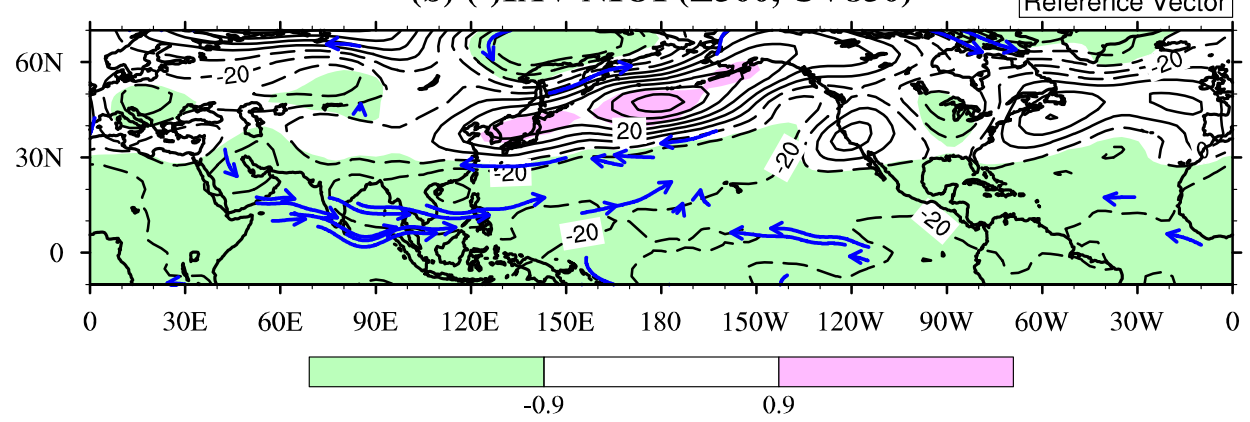

(c) Scatter Plot

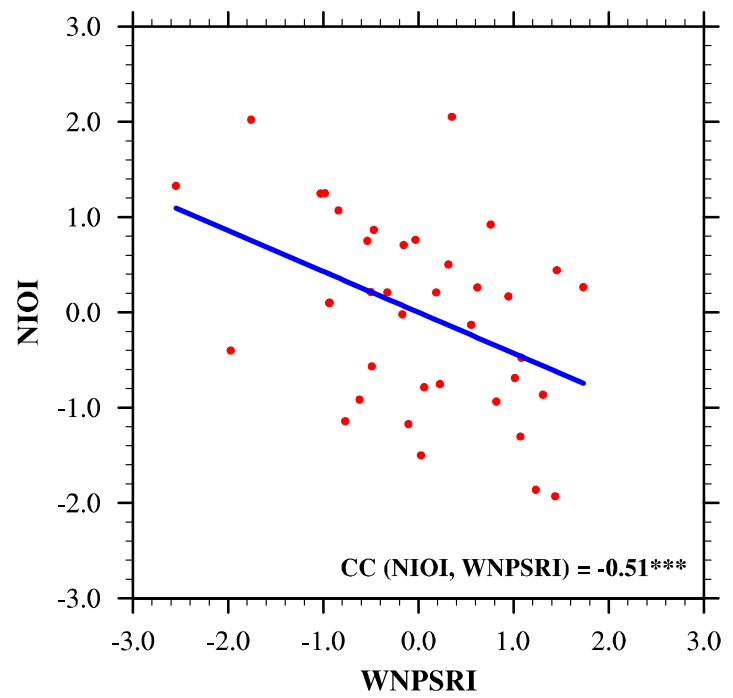

the factor appears to be sustained for a decadal period. Here, we focus on the sea surface temperature distribution to identify a decadal timescale source. In Fig. 4a, the most dominant pattern against decadal EASRI is shown over the Pacific. It illustrates the negative phase of the Interdecadal Pacific Oscillation pattern (IPO)-like pattern (Henley et al. 2015). The IPO index is derived from differences in the area-averaged SSTA over the regions between the central Pacific $\left(10^{\circ} \mathrm{S}-10^{\circ} \mathrm{N}, 170^{\circ} \mathrm{E}-90^{\circ} \mathrm{W}\right)$, northwest $\left(25^{\circ}\right.$ $\mathrm{N}-45^{\circ} \mathrm{N}, 140^{\circ} \mathrm{E}-145^{\circ} \mathrm{W}$ ), and southwest Pacific (50
$\mathrm{S}-15^{\circ} \mathrm{S}, 150^{\circ} \mathrm{E}-160^{\circ} \mathrm{W}$ ) for $1979-2016$. And then it is averaged for JJA and is filtered with an 8-15 year band. We represent the regressed surface temperature and atmospheric circulation anomalies against EASRI on the decadal timescale to deduce the physical mechanism modulating the decadal phase of EASRI (Fig. 9a and b). Figure 9 bears resemblance to regressed distributions against decadal EASRI, especially prominent subtropical anti-cyclonic circulation anomalies over North Pacific. 

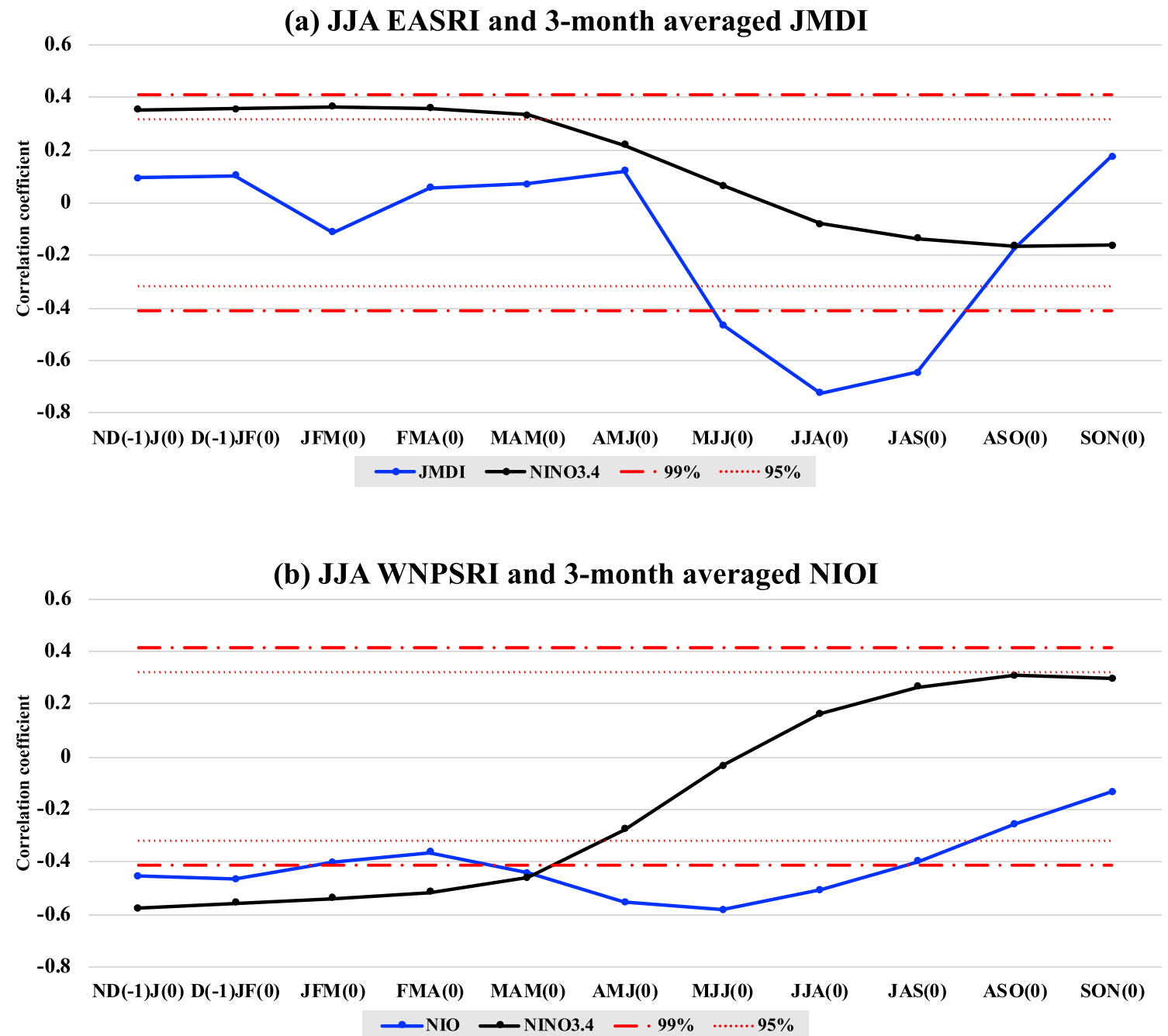

Fig. 7 The correlation coefficient between 3-month averaged (a) JMDI and Niño 3.4 with boreal summer (Jun-Jul-Aug, JJA) EASRI, and (b) NIOI and Niño 3.4 with JJA WNPSRI. The blue line indicates the relationship between JMDI (NIOI) and EASRI (WNPSRI)

We propose a possible mechanism for how the negative IPO pattern affects the intensity of rainfall over East Asia for a decadal period as follows. When the negative IPO pattern persists for a decade due to its longevity, the anomalous trade wind and an easterly wind become overwhelming due to a La Niña-like SSTA pattern. These anomalous wind flows provide an invigorated North Pacific subtropical high (NPSH). The anomalous southeasterly wind over East Asia is remarkable along the western flank of the NPSH. The precipitation generally depends on not only the monsoonal flow but also the adequacy of moisture transported by the monsoonal flow. Although the moisture convergence distribution against decadal EASRI is not consistent with the horizontal wind field on a decadal timescale, the southeasterly wind flow by the strengthened NPSH is likely to play a role in supplying moisture over East Asia. The scatter plot and black line means the correlation coefficient of Niño 3.4 with EASRI (WNPSRI). The red dotted (dashed dot) line denotes statistical significance at the $95 \%$ (99\%) confidence level based on the Student's t-test

exhibits a negative relationship between decadal EASRI and IPO index and a correlation coefficient of -0.65 (Fig. 9c).

In the decadal timescale, an effective number of degrees of freedom gets smaller than that on the interannual timescale due to long-term bandpass filtering. Because of the small equivalent sample size, it is difficult to perform a statistically significant relationship between decadal EASRI and IPO index. The correlation coefficient value of -0.65 is below the $90 \%$ confidence level in Student's t-test with an effective number of degrees of freedom. Although it records insignificant, the regressed distributions against decadal EASRI resemble those against the decadal IPO index in Figs. 4 and 9. We explore the pattern correlation coefficients between the spatial regression coefficient over the EASR region. It records a high value in surface temperature (0.97), horizontal wind at the lower level (Zonal wind: 0.84, 
(a) (-)IAV JMDI (PRCP)

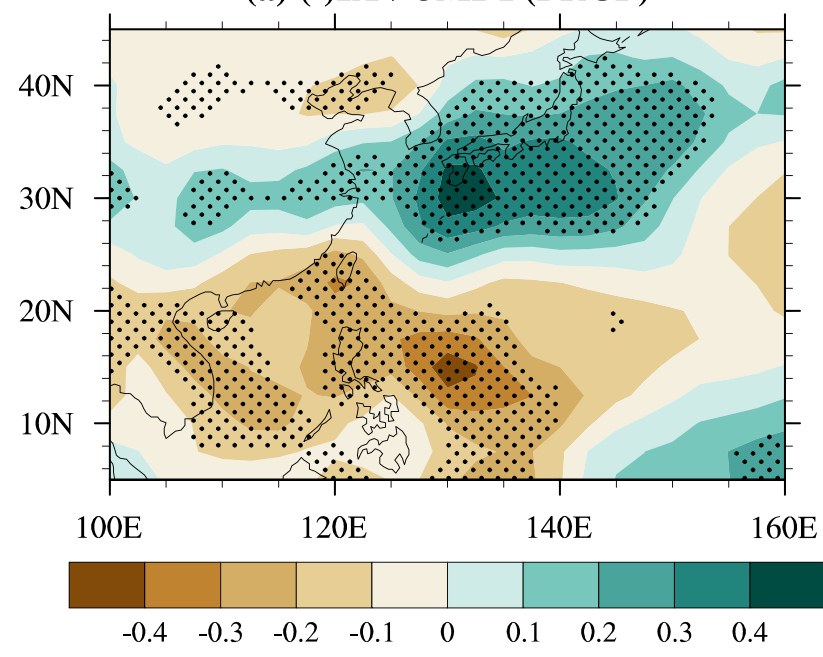

(b) (-)IAV NIOI (PRCP)

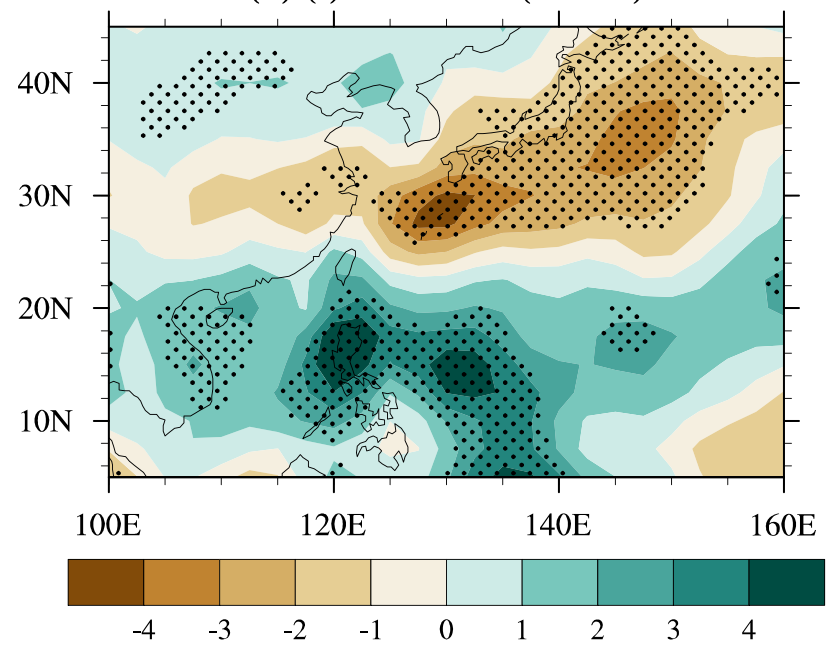

Fig. 8 Spatial distribution of regressed precipitation (unit: $\mathrm{mm} \mathrm{day}^{-1}$ ) with respect to the negative phase of $\mathbf{a}$ JMDI and $\mathbf{b}$ NIOI. The shading denotes the regression coefficient in precipitation (unit: mmday $^{-1}$ ) and the stippling represents the significance at the $90 \%$ confidence level based on the Student's t-test

Meridional wind: 0.87), and geopotential height (0.96) at $500 \mathrm{hPa}$, respectively. Therefore, we support that the negative phase of IPO may contribute to increasing the frequency of intensive rainfall over East Asia on the decadal timescale.

\subsubsection{WNPSRI}

Unlike regressed patterns upon the interannual EASRI and WNSRI, the decadal regression distributions have less resemblance with an insignificant relationship between decadal EASRI and WNPSRI. In the decadal EASRI, the significant patterns are observed throughout, but the most dominant pattern is SSTA over the Pacific (Fig. 4a). In contrast, the most notable feature of the regressed distribution of WNPSRI comparing to that for EASRI is a less significant pattern over the Pacific but dominant SSTA over the Atlantic (Fig. 4b). The considerably dominant SSTA pattern has features as tripolar centers over the North Atlantic. We design the North Atlantic tri-pole index (NATI) based on regions that are significantly dominant in the regressed SSTA distribution against the decadal WNPSRI. This index is derived from differences in the area-averaged SSTA between sections over the tropical Atlantic $\left(0^{\circ}-10^{\circ} \mathrm{N}, 10^{\circ} \mathrm{W}-45^{\circ} \mathrm{W}\right)$, over the western North Atlantic $\left(35^{\circ} \mathrm{N}-45^{\circ} \mathrm{N}, 60^{\circ} \mathrm{W}-70^{\circ}\right.$ $\mathrm{W})$, and the North Atlantic $\left(50^{\circ} \mathrm{N}-60^{\circ} \mathrm{N}, 25^{\circ} \mathrm{W}-45^{\circ} \mathrm{W}\right)$. And then, it is averaged for JJA and filtered by an 8-15 year band.

In the regressed anomalous SST and SAT distribution, the significant tri-pole anomaly pattern is displayed in Fig. 10a, like Fig. 4b. However, a warming signal over the central Pacific is also dominant, unlike Fig. 4b. The relationship between North Atlantic Oscillation (NAO) associated with North Atlantic tri-pole (NAT) mode and SSTA patterns over the Pacific has been widely accepted. The Asian summer monsoon system is controlled by the empirical model based on the combination of NAO and ENSO (Gershunov and Barnett 1998; Wu et al., 2009). To confirm the atmospheric circulation activity, geopotential height and the superposed significant wave activity flux (WAF) at $200 \mathrm{hPa}$ are shown, not the horizontal wind at a lower level (Takaya and Nakamura 2001). The wave activity flux is a helpful tool to capture the propagation of stationary or migratory wave disturbances. The anomalous atmospheric circulation distribution is similar to what appeared in the WNPSRI and the originated wave is propagating from North Atlantic to west-central Asia. The anomalous cyclonic circulation covers Eurasian continents and it modifies the surrounding environment of the WNP region. Following Zuo et al. (2013), the teleconnection pattern that emanates from the North Atlantic to Asia may be maintained by anomalous diabatic heating in the North Atlantic. However, it is difficult to infer the regressed pattern that is independent of ENSO because the relationship between Pacific and NAT mode is meaningful. The scatter plot is represented with a correlation coefficient of $0.81 * *$ which is statistically significant above the $95 \%$ confidence level (Fig. 10c). Therefore, the NAT pattern may have an influence on rainfall patterns over the WNP on the decadal timescale.

Then, how tripolar SST anomalies over the North Atlantic influence can reach over the WNP region? The interaction between oceanic-atmospheric systems in the North Atlantic region exhibits strong variability from seasonal to long-term timescales. Especially, the spring NAO activity is accompanied by a meridional shift of the Atlantic jet stream. And the positive phase of NAO is tied to a poleward shift of 
Fig. 9 Spatial distribution of regressed (a) surface temperature (contour, unit: $\mathrm{K}$ ) and (b) geopotential height at $500 \mathrm{hPa}$ (contour, unit: gpm) and horizontal wind at $850 \mathrm{hPa}$ (vector, unit: $\mathrm{ms}^{-1}$ ) distribution against the negative phase of IPO index. c The scatter plot between decadal EASRI and IPO index and their correlation coefficient. The shading from light to dark color in the surface temperature distribution indicates the statistical significance at the 90, 95, and $99 \%(0.9,0.95$, and 0.99$)$ confidence level and that in the geopotential height distribution show the significance at $90 \%$ (0.9) confidence level evaluated by the Student's t-test based on the effective number of degrees of freedom (a) (-)DV IPO index (SST, SAT)
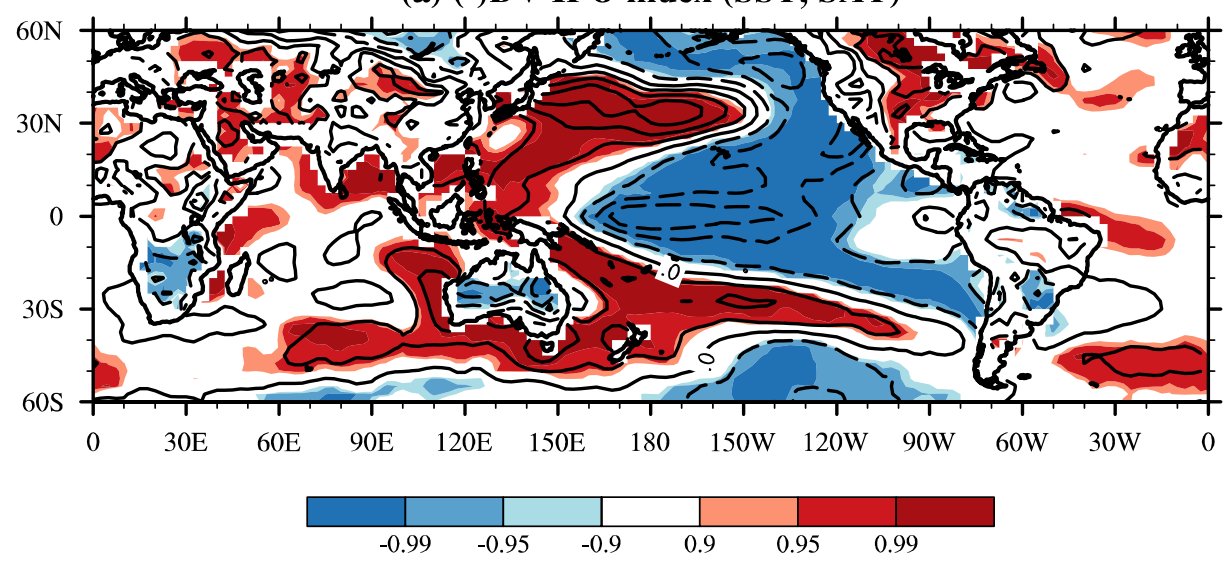

(b) (-)DV IPO index (Z500, UV850)

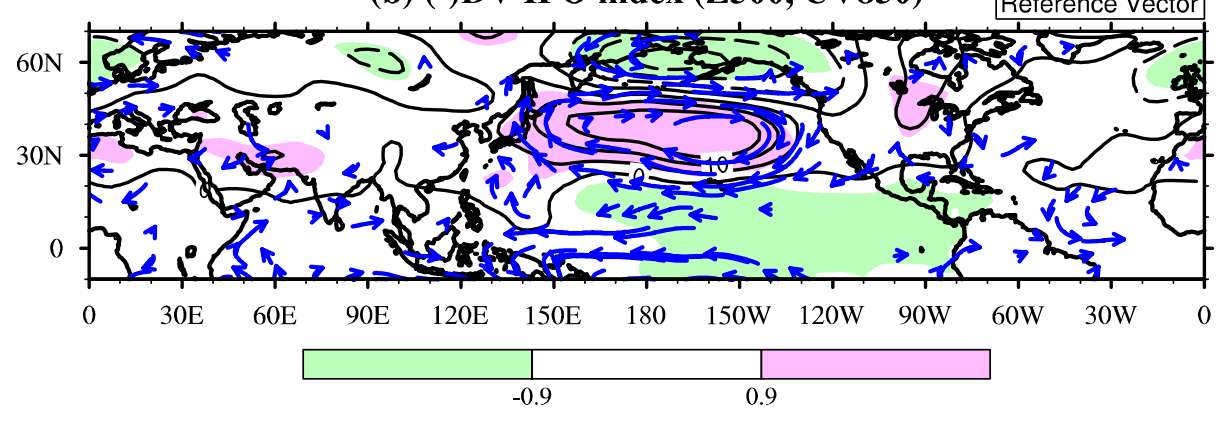

(c) Scatter Plot

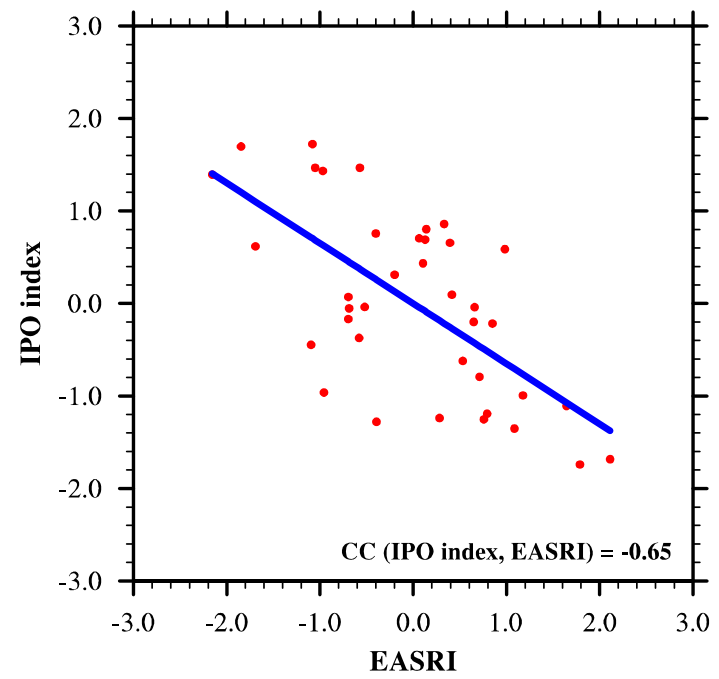

the Atlantic jet stream. The region, where the wind speed is weakening, is within the latitude $30^{\circ} \mathrm{N}-45^{\circ} \mathrm{N}$, and the enhanced wind speed is observed within areas south of $30^{\circ}$ $\mathrm{N}$ and north of $45^{\circ} \mathrm{N}$ at the upper level. Due to the quasibarotropic structure in the mid-latitudes, the intensity and displacement of the upper-level jet stream vary in-phase with those in lower level wind distribution. The decreasing wind speed often favors anomalous warm SST and vice versa by latent heat flux exchange and a tri-polar SSTA occurs over the North Atlantic (Marshall et al. 2001; Xie 2004; Pan 2005; Deser et al. 2010). Finally, the spring NAT pattern caused by the spring NAO may be able to span across the season, into summer. Zheng et al. (2016) showed that the boreal summer NAO phase, which is an in-phase relationship 
Fig. 10 The regressed (a) surface temperature (contour, unit: K) and (b) geopotential height at $200 \mathrm{hPa}$ (contour, unit: gpm) and wave activity flux at $200 \mathrm{hPa}$ (vector, unit: $\mathrm{m}^{2} \mathrm{~s}^{-2}$ ) distribution against the NATI. c The scatter plot between decadal WNPSRI and NATI and their correlation coefficient. The shading from light to dark color in the surface temperature distribution indicates the statistical significance at the 90,95 , and $99 \%(0.9,0.95$, and 0.99$)$ confidence level and that in the geopotential height distribution show the significance at $90 \%$ (0.9) confidence level evaluated by the Student's t-test based on the effective number of degrees of freedom (a) DV NATI (SST, SAT)

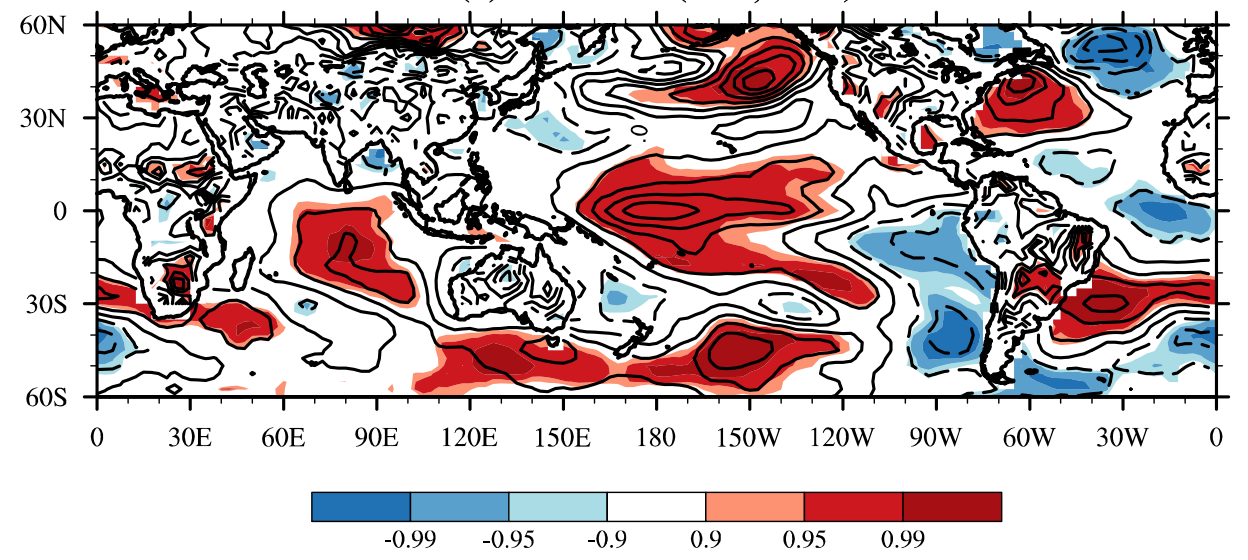

(b) DV NATI (Z200, WAF200)

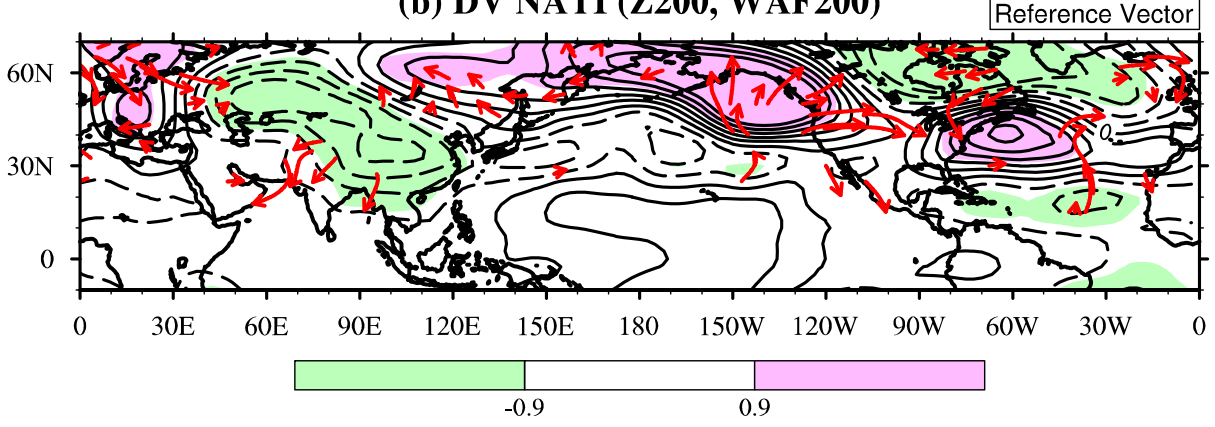

(c) Scatter Plot

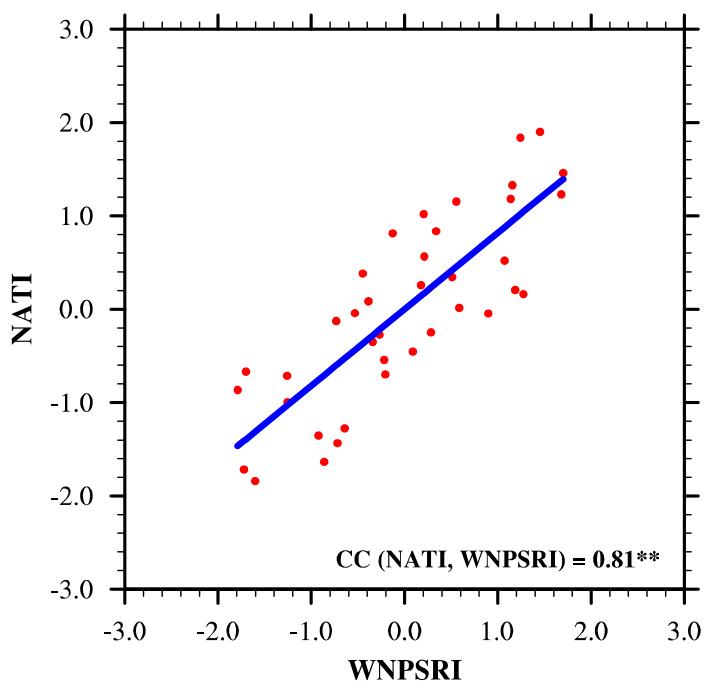

with spring NAO, has an instantaneous influence on SSTA over the North Atlantic. Several studies have appealed the possible influence of the ocean-atmospheric interaction over the North Atlantic on global climate and weather including Asia (Marshall et al. 2001; Ogi et al. 2003; Ding and Wang 2005; Lu et al. 2006; Sung et al. 2006). The wave response related to the NAO (NAT) is induced with the upper-level convergence over the Mediterranean Sea and wave train paths represent. Although the wave train path in this study deviates from the path which is explained in previous studies, they suggest the linkage between the North Atlantic and affected wave train. 


\section{Summary and discussion}

Numerous studies have investigated not only interannual but also longer timescale variabilities. Especially, they have confirmed the longer timescale variation in Asian monsoon by examining the notable phase transition and shift in the interannual relationship between monsoons and several climate patterns. However, in this study, we attempt to find the related climate phenomenon coinciding with the periodicity of monsoons. Before comparing to monsoon indices and climate distribution, we identify the periodicity of monsoon via wavelet analysis and apply the bandpass filtering to isolate into interannual and decadal variabilities. Few studies have performed the extracted monsoon time-series via bandpass filtering, but not in background fields such as geopotential height, precipitation, horizontal wind, and surface temperature. We employ the bandpass filtering in background fields as well as indices.

Following wavelet analysis for EASRI and WNPSRI, the present study interprets the major variabilities, which are interannual and decadal timescales, and proposes their drivers. The interannual variations in both indices are significantly dominant. The decadal variation is clear in the wavelet analysis of WNPSRI but it is less in EASRI. To extract the interannual and decadal variabilities, both indices apply the bandpass filtering for 1-7 and 8-15 year bands. The interannual EASRI is significantly associated with the meridional shift of the subtropical jet stream. When a subtropical jet stream shifts equatorward comparing to the climatology over the south region of $40^{\circ} \mathrm{N}$, an anomalous westerly wind at $200 \mathrm{hPa}$ overlaps over the southern section of Northeast Asia. The anomalous westerly wind may appear at the lower level and induce the anomalous cyclonic circulation over East Asia. In terms of WNPSRI, the anomalous cooling signal over NIO is significantly related to the interannual WNPSRI. The preceding and simultaneous cooling over NIO produces the anomalous precipitation modulated by a Matsuno-Gill pattern. The regressed rainfall patterns upon JMDI and NIOI are out of phase with each other, and the anomalous precipitation reduction is shown in WNP and East Asia, respectively. Therefore, meridional displacement of the subtropical jet stream and thermal conditions over the NIO are not just for adjusting rainfall on East Asia and the WNP, but they also contribute to the anomalous meridional dipole pattern with high covariance.

In the decadal timescale, we mark the large heat capacity and persistence of the oceanic variable as external forcing, not the regional approach. The factor that increases the frequency of potential rainfall events over East Asia in decadal timescale is the negative phase of the IPO pattern with an anomalous anti-cyclonic circulation over the North Pacific. The subtropical high over North Pacific is enhanced by the La Niña-like pattern and generates anomalous southeasterly wind along the western flank of it. This southeasterly flow may play a role in supplying moisture over East Asia on the decadal timescale. As illustrated in Figs. 2 and 9, the EASRI has a small amplitude in decadal variability and the correlation coefficient between the decadal EASRI and IPO is below $90 \%$ confidence level due to the small equivalent sample size in the decadal timescale. Besides, the analysis period is too short to identify the statistical significance in the relationship between the EASRI and IPO. However, the regressed SST and atmospheric circulation distributions against decadal EASRI and IPO index resemble greatly. Therefore, we propose the negative phase of IPO to increase the frequency of strong rainfall over East Asia. Especially, the frequent occurrence of equatorial central Pacific (CP) El Niño and enhanced mean trade wind have been documented in previous studies (Yeh et al. 2009; Xiang et al. 2013; Huang et al. 2018). The time-series of decadal variability of EASR showed a large amplitude of phase change in the late 1990s (Fig. 2c) and the $\mathrm{CP}$ cooling distribution in boreal summer closely bears resemblance to the negative phase of IPO. The IPO represents a long-term phase on Pacific with long-lived ENSO patterns and may include the CP ENSO mode. Therefore, we expect the abrupt occurrence of CP ENSO may contribute to the temporal increasing of amplitude in decadal EASR.

The possible factor to modulate the rainfall patterns over the WNP on the decadal timescale is an anomalous SST tri-pole pattern over the North Atlantic. The NAO during boreal spring and summer influences the anomalous SST distribution over the North Atlantic, as NAT pattern. The wave activity flux forced by diabatic heating over the NAT pattern originates from the North Atlantic to west-central Asia. The centers of cyclonic circulation anomalies against the NAT pattern coincide with those observed on the decadal timescale of WNPSRI. The large cyclonic circulation which covers most of the area of Eurasian continents may modify the surrounding environment for the enhanced WNP rainfall in the decadal timescale. Eventually, these decadal factors control only each monsoon and they do not record significant covariance.

There is still a limitation in this study. It is difficult to identify the statistical signature of variability with decadal timescale due to the short analyzed period. The variance contribution of WNPSRI on the decadal timescale accounts for a small contribution than interannual timescale. However, it is considered crucially enough to influence on total variability and is worth investigating. In contrast, in the EASRI, the decadal contribution is too small. Thus, we attempt to use additional precipitation datasets to elucidate 
the general characteristics by using Asian Precipitation Highly Resolved Observational Data Integration Towards Evaluation (APHRODITE) gridded precipitation dataset (Yatagai et al. 2012). Although the APHRODITE is a continental scale dataset, the correlation coefficient between EASR indices by GPCP and APHRODITE is significantly high $\left(0.72^{* * *}\right)$ for $1979-2007$. In the period for 1951-2007, the decadal contribution in APHRODITE EASRI becomes large in the power spectrum (not shown). Eventually, EASRI has prominent decadal variability during a longer period and the dominant periodicity in EASRI depends on the analyzed period.

Acknowledgements We acknowledge the data providers in NCEPNCAR (https://www.esrl.noaa.gov/psd/data/gridded/data.ncep.reana lysis.html), ERA-INTERIM (https://apps.ecmwf.int/datasets/data/inter im-full-moda/levtype=sfc/), GPCP (https://www.esrl.noaa.gov/psd/ data/gridded/data.gpcp.html), ERSST version 5 (https://www.esrl.noaa. gov/psd/data/gridded/data.noaa.ersst.v5.html), Niño 3.4 index (https ://climatedataguide.ucar.edu/climate-data/nino-sst-indices-nino-12-334-4-oni-and-tni), APHRODITE (https://aphrodite.st.hirosaki-u.ac.jp/ products.html).

Author contributions K-JH designed the study, SK and K-JH performed the analysis and wrote the manuscript.

Funding This study was supported by the Institute for Basic Science (IBS), Republic of Korea, under IBS-R028-D1.

\section{Compliance with ethical standards}

Conflict of interest The authors declare that they have no conflict of interest.

Open Access This article is licensed under a Creative Commons Attribution 4.0 International License, which permits use, sharing, adaptation, distribution and reproduction in any medium or format, as long as you give appropriate credit to the original author(s) and the source, provide a link to the Creative Commons licence, and indicate if changes were made. The images or other third party material in this article are included in the article's Creative Commons licence, unless indicated otherwise in a credit line to the material. If material is not included in the article's Creative Commons licence and your intended use is not permitted by statutory regulation or exceeds the permitted use, you will need to obtain permission directly from the copyright holder. To view a copy of this licence, visit http://creativecommons.org/licenses/by/4.0/

\section{References}

Adler RF, Huffman GJ, Chang A et al (2003) The version-2 global precipitation climatology project (GPCP) monthly precipitation analysis (1979-present). J Hydrometeorol 4:1147-1167. https://doi. org/10.1175/1525-7541(2003)004\%3c1147:tvgpcp\%3e2.0.co;2

Bretherton CS, Widmann M, Dymnikov VP et al (1999) The effective number of spatial degrees of freedom of a time-varying field. J Clim 12:1990-2009. https://doi.org/10.1175/15200442(1999)012\%3c1990:TENOSD\%3e2.0.CO;2

Chen J, Bordoni S (2016) Early summer response of the East Asian summer monsoon to atmospheric $\mathrm{CO}_{2}$ forcing and subsequent sea surface warming. J Clim 29:5431-5446. https://doi. org/10.1175/JCLI-D-15-0649.1

Dee DP, Uppala SM, Simmons AJ et al (2011) The ERA-Interim reanalysis: configuration and performance of the data assimilation system. Q J R Meteorol Soc 137:553-597. https://doi. org/10.1002/qj.828

Deser C, Alexander MA, Xie S-P, Phillips AS (2010) Sea surface temperature variability: patterns and mechanisms. Annu Rev Mar Sci 2:115-143. https://doi.org/10.1146/annurev-marin e-120408-151453

Ding Y (2007) The variability of the Asian summer monsoon. J Meteorol Soc Jpn 85B:21-54. https://doi.org/10.2151/ jmsj.85B.21

Ding Y, Chan JCL (2005) The East Asian summer monsoon: an overview. Meteorol Atmos Phys 89:117-142. https://doi.org/10.1007/ s00703-005-0125-z

Ding Q, Wang B (2005) Circumglobal teleconnection in the Northern Hemisphere summer. J Clim 18:3483-3505. https://doi. org/10.1175/JCLI3473.1

Ding R, Ha KJ, Li J (2010) Interdecadal shift in the relationship between the East Asian summer monsoon and the tropical Indian Ocean. Clim Dyn 34:1059-1071. https://doi.org/10.1007/s0038 2-009-0555-2

Enomoto T, Hoskins BJ, Matsuda Y (2003) The formation mechanism of the Bonin high in August. Q J R Meteorol Soc 129:157-178. https://doi.org/10.1256/qj.01.211

Gershunov A, Barnett TP (1998) Interdecadal modulation of ENSO teleconnections. Bull Am Meteorol Soc 79:2715-2725. https://doi. org/10.1175/1520-0477(1998)079\%3c2715:IMOET\%3e2.0.CO;2

Gong DY, Ho CH (2003) Arctic oscillation signals in the East Asian summer monsoon. J Geophys Res D Atmos 108:1-6. https://doi. org/10.1029/2002jd002193

Gong DY, Yang J, Kim SJ et al (2011) Spring Arctic oscillation-East Asian summer monsoon connection through circulation changes over the western North Pacific. Clim Dyn 37:2199-2216. https:// doi.org/10.1007/s00382-011-1041-1

Goswami BN, Madhusoodanan MS, Neema CP, Sengupta D (2006) A physical mechanism for North Atlantic SST influence on the Indian summer monsoon. Geophys Res Lett 33:1-4. https://doi. org/10.1029/2005GL024803

Gu W, Li C, Wang X et al (2009) Linkage between Mei-yu precipitation and North Atlantic SST on the decadal timescale. Adv Atmos Sci 26:101-108. https://doi.org/10.1007/s00376-009-0101-5

Guan Z, Yamagata T (2003) The unusual summer of 1994 in East Asia: IOD teleconnections. Geophys Res Lett. https://doi. org/10.1029/2002gl016831

Ha KJ, Yun KS, Jhun JG, Li J (2009) Circulation changes associated with the interdecadal shift of Korean August rainfall around late 1960s. J Geophys Res Atmos 114:1-9. https://doi. org/10.1029/2008JD011287

Ha KJ, Heo KY, Lee SS et al (2012) Variability in the East Asian monsoon: a review. Meteorol Appl 19:200-215. https://doi. org/10.1002/met.1320

Henley BJ, Gergis J, Karoly DJ et al (2015) A tripole index for the interdecadal pacific oscillation. Clim Dyn 45:3077-3090. https:// doi.org/10.1007/s00382-015-2525-1

Huang R, Chen J, Wang L, Lin Z (2013) Erratum to Characteristics, processes, and causes of the spatio-temporal variabilities of the East Asian monsoon system. Adv Atmos Sci 30:541. https://doi. org/10.1007/s00376-013-0001-6

Huang B, Thorne PW, Banzon VF et al (2017) Extended reconstructed Sea surface temperature, Version 5 (ERSSTv5): upgrades, validations, and intercomparisons. J Clim 30:8179-8205. https://doi. org/10.1175/JCLI-D-16-0836.1

Huang Y, Wang B, Li X, Wang H (2018) Changes in the influence of the western Pacific subtropical high on Asian summer monsoon 
rainfall in the late 1990s. Clim Dyn 51:443-455. https://doi. org/10.1007/s00382-017-3933-1

Kalnay E, Kanamitsu M, Kistler R et al (1996) The NCEP/NCAR 40-year Reanalysis Project. Bull Am Meteorol Soc 77:437-471. https://doi.org/10.1175/1520-0477(1996)077<0437:TNYRP $>2.0 . \mathrm{CO} ; 2$

Kim S, Ha KJ, Ding R, Li J (2018) Re-examination of the decadal change in the relationship between the East Asian summer monsoon and Indian Ocean SST. Atmosphere (Basel) 9:395. https:// doi.org/10.3390/atmos9100395

Kripalani RH, Oh JH, Chaudhari HS (2010) Delayed influence of the Indian Ocean dipole mode on the East Asia-West Pacific monsoon: Possible mechanism. Int J Climatol 30:197-209. https:// doi.org/10.1002/joc. 1890

Kwon MH, Jhun JG, Ha KJ (2007) Decadal change in east Asian summer monsoon circulation in the mid-1990s. Geophys Res Lett 34:1-6. https://doi.org/10.1029/2007GL031977

Lau KM (1992) East Asian summer monsoon rainfall variability and climate teleconnection. J Meteorol Soc Jpn 70:211-242. https:// doi.org/10.2151/jmsj1965.70.1B_211

Lau KM, Yang GJ, Shen SH (1988) Seasonal and intraseasonal climatology of summer monsoon rainfall over East Asia. Mon Weather Rev 116:18-37. https://doi.org/10.1175/15200493(1988)116<0018:SAICOS>2.0.CO;2

Lee SS, Vinayachandran PN, Ha KJ, Jhun JG (2010) Shift of peak in summer monsoon rainfall over Korea and its association with El Niño-Southern Oscillation. J Geophys Res Atmos 115:1-15. https ://doi.org/10.1029/2009JD011717

Lee EJ, Ha KJ, Jhun JG (2014) Interdecadal changes in interannual variability of the global monsoon precipitation and interrelationships among its subcomponents. Clim Dyn 42:2585-2601. https ://doi.org/10.1007/s00382-013-1762-4

Li J, Zeng Q (2002) A unified monsoon index. Geophys Res Lett 29:1151-1154. https://doi.org/10.1029/2001gl013874

Lu R, Dong B, Ding H (2006) Impact of the Atlantic multidecadal oscillation on the Asian summer monsoon. Geophys Res Lett 33:1-5. https://doi.org/10.1029/2006GL027655

Marshall J, Johnson H, Goodmann J (2001) A study of the interaction of the North Atlantic oscillation with ocean circulation. J Clim 14:1399-1421. https://doi.org/10.1175/15200442(2001)014\%3c1399:ASOTIO\%3e2.0.CO;2

Murakami T, Matsumoto J (1994) Summer monsoon over the Asian continent and western north pacific. J Meteorol Soc Jpn 72:719745. https://doi.org/10.2151/jmsj1965.72.5_719

Ninomiya K, Akiyama T (1992) Multi-scale features of Baiu, the summer monsoon over Japan and the East Asia. J Meteorol Soc Jpn 70:467-495. https://doi.org/10.2151/jmsj1965.70.1B_467

Nitta T (1987) Convective activities in the tropical western pacific and their impact on the northern hemisphere summer circulation. J Meteorol Soc Jpn 65:373-390. https://doi.org/10.2151/jmsj1 965.65.3_373

Ogi M, Tachibana Y, Yamazaki K (2003) Impact of the wintertime North Atlantic Oscillation (NAO) on the summertime atmospheric circulation. Geophys Res Lett 30:2-5. https://doi. org/10.1029/2003GL017280

Oh H, Ha KJ (2015) Thermodynamic characteristics and responses to ENSO of dominant intraseasonal modes in the East Asian summer monsoon. Clim Dyn 44:1751-1766. https://doi.org/10.1007/ s00382-014-2268-4

Oh H, Ha KJ (2016) Prediction of dominant intraseasonal modes in the East Asian-western North Pacific summer monsoon. Clim Dyn 47:2025-2037. https://doi.org/10.1007/s00382-015-2948-8

Oh H, Ha KJ (2020) Role of the surface boundary conditions in boreal spring on the interannual variability of the multistage evolution of the East Asian summer monsoon. J Clim 33:18451861. https://doi.org/10.1175/JCLI-D-19-0249.1
Pan LL (2005) Observed positive feedback between the NAO and the North Atlantic SSTA tripole. Geophys Res Lett 32:1-4. https:// doi.org/10.1029/2005GL022427

Park HS, Lintner BR, Boos WR, Seo KH (2015) The effect of midlatitude transient eddies on monsoonal southerlies over eastern China. J Clim 28:8450-8465. https://doi.org/10.1175/ JCLI-D-15-0133.1

Shukla J, Mooley DA (1987) Empirical prediction of the summer monsoon rainfall over India. Mon Weather Rev 115:695-703. https://doi.org/10.1175/1520-0493(1987)115\%3c0695:epots $\mathrm{m} \% 3 \mathrm{e} 2.0 . \mathrm{co} ; 2$

Sung MK, Kwon WT, Baek HJ et al (2006) A possible impact of the North Atlantic Oscillation on the east Asian summer monsoon precipitation. Geophys Res Lett 33:3-6. https://doi. org/10.1029/2006GL027253

Takaya K, Nakamura H (2001) A formulation of a phase-independent wave-activity flux for stationary and migratory quasigeostrophic eddies on a zonally varying basic flow. J Atmos Sci 58:608-627. https://doi.org/10.1175/1520-0469(2001)058\%3c0608:AFOAP I\%3e2.0.CO;2

Torrence C, Compo GP (1998) A practical guide to wavelet analysis. Bull Am Meteorol Soc 79:61-78. https://doi.org/10.1175/15200477(1998)079\%3c0061:APGTWA\%3e2.0.CO;2

Wang B, Fan Z (1999) Choice of South Asian Summer Monsoon Indices. Bull Am Meteorol Soc 80:629-638. https:// doi.org/10.1175/1520-0477(1999)080\%3c0629:COSAS $\mathrm{M} \% 3 \mathrm{e} 2.0 . \mathrm{CO} ; 2$

Wang B, Ho L (2002) Rainy season of the Asian-Pacific summer monsson. J Clim 15:386-398. https://doi.org/10.1175/15200442(2002)015\%3c0386:RSOTAP\%3e2.0.CO;2

Wang B, Wu R, Lau KM (2001) Interannual variability of the asian summer monsoon: contrasts between the Indian and the Western North Pacific-East Asian monsoons. J Clim 14:4073-4090. https://doi.org/10.1175/1520-0442(2001)014\%3c4073:IVOTA $\mathrm{S} \% 3 \mathrm{e} 2.0 . \mathrm{CO} ; 2$

Wang B, Liu J, Kim HJ et al (2013) Northern Hemisphere summer monsoon intensified by mega-El Niño/southern oscillation and Atlantic multidecadal oscillation. Proc Natl Acad Sci USA 110:5347-5352. https://doi.org/10.1073/pnas.1219405110

Wang B, Li J, Cane MA et al (2018) Toward predicting changes in the land monsoon rainfall a decade in advance. J Clim 31:2699-2714. https://doi.org/10.1175/JCLI-D-17-0521.1

Wu R, Wang B (2000) Interannual variability of summer monsoon onset over the western North Pacific and the underlying processes. J Clim 13:2483-2501. https://doi.org/10.1175/15200442(2000)013\%3c2483:IVOSMO\%3e2.0.CO;2

Wu Z, Wang B, Li J, Jin FF (2009) An empirical seasonal prediction model of the east Asian summer monsoon using ENSO and NAO. J Geophys Res Atmos 114:1-13. https://doi.org/10.1029/2009J D011733

Wu Z, Li J, Jiang Z et al (2012) Possible effects of the North Atlantic Oscillation on the strengthening relationship between the East Asian Summer monsoon and ENSO. Int J Climatol 32:794-800. https://doi.org/10.1002/joc.2309

Xiang B, Wang B, Li T (2013) A new paradigm for the predominance of standing Central Pacific Warming after the late 1990s. Clim Dyn 41:327-340. https://doi.org/10.1007/s00382-012-1427-8

Xie SP (2004) Satellite observations of cool ocean-atmosphere interaction. Bull Am Meteorol Soc 85:195-208. https://doi.org/10.1175/ BAMS-85-2-195

Xie SP, Hu K, Hafner J et al (2009) Indian Ocean capacitor effect on Indo-Western pacific climate during the summer following El Niño. J Clim 22:730-747. https://doi.org/10.1175/2008JCLI25 44.1 
Yang J, Liu Q, Xie SP et al (2007) Impact of the Indian Ocean SST basin mode on the Asian summer monsoon. Geophys Res Lett 34:1-5. https://doi.org/10.1029/2006GL028571

Yatagai A, Kamiguchi K, Arakawa O et al (2012) Aphrodite constructing a long-term daily gridded precipitation dataset for Asia based on a dense network of rain gauges. Bull Am Meteorol Soc 93:1401-1415. https://doi.org/10.1175/BAMS-D-11-00122.1

Yeh SW, Kug JS, Dewitte B et al (2009) El Niño in a changing climate. Nature 461:511-514. https://doi.org/10.1038/nature08316

Yim SY, Wang B, Liu J, Wu Z (2014) A comparison of regional monsoon variability using monsoon indices. Clim Dyn 43:1423-1437. https://doi.org/10.1007/s00382-013-1956-9

Yun J, Ha KJ, Jo YH (2018) Interdecadal changes in winter surface air temperature over East Asia and their possible causes. Clim Dyn 51:1375-1390. https://doi.org/10.1007/s00382-017-3960-y

Zhang R, Sumi A, Kimoto M (1996) Impact of El Nino on the East Asian monsoon: a diagnostic study of the 86/87 and 91/92 events. J Meteorol Soc Jpn 74:49-62. https://doi.org/10.2151/jmsj1 965.74.1_49
Zhang Y, Kuang X, Guo W, Zhou T (2006) Seasonal evolution of the upper-tropospheric westerly jet core over East Asia. Geophys Res Lett 33:3-6. https://doi.org/10.1029/2006GL026377

Zheng F, Li J, Li Y et al (2016) Influence of the summer NAO on the spring-NAO-based predictability of the East Asian summer monsoon. J Appl Meteorol Climatol 55:1459-1476. https://doi. org/10.1175/JAMC-D-15-0199.1

Zuo J, Li W, Sun C et al (2013) Impact of the North Atlantic sea surface temperature tripole on the East Asian summer monsoon. Adv Atmos Sci 30:1173-1186. https://doi.org/10.1007/s0037 6-012-2125-5

Publisher's Note Springer Nature remains neutral with regard to jurisdictional claims in published maps and institutional affiliations. 